\title{
Southern African cosmogenic geomythology ("following a star") of the Zion Christian Church
}

\author{
Richard P. Wade*, Patrick G. Eriksson, Hannes C.J. deW Rautenbach and G.A. Duncan \\ University of Pretoria, Pretoria 002, South Africa \\ *Author for correspondence e-mail: richard.peter.wade@gmail.com
}

\begin{abstract}
Oral traditions and indigenous knowledge of the Limpopo Province in South Africa suggest a meteor event occurred in the area several decades ago. This relatively recent significant meteor event with associated features may have contributed to a revitalization of 13th century ancestral geomythology, also based on an astronomical event, and to an ideological transformation that augmented a vast sociopolitical belief system in sub-Saharan Africa.
\end{abstract}

Keywords: geomythology, Zion Christian Church, meteor, impact crater, archaeoastronomy, Lemba, indigenous knowledge systems, RX J0852.0-4622, G266.2-1.2, Great Zimbabwe, oral tradition

\section{INTRODUCTION}

A study of South African and Zimbabwean indigenous knowledge has led to a preliminary understanding of the legends and myths that deal with how the ancestors of the current Limpopo Province populations, as recorded by the BaLemba/BaSena/VaMwenye peoples, came to establish the Zimbabwe "civilization" (Great Zimbabwe Cultural Complex) and how the earliest metalworking farmers and traders were led to build Great Zimbabwe (20 $0^{\circ} 16^{\prime} 8 \mathrm{~A}$ S: $30^{\circ} 56^{\prime} 17 \mathrm{~A}$ E) by following a star (Arenstein \& Hamese, 2000; Mathivha, 1992; Müller, 2000; Van Warmelo, 1940; Wade, 2009). It is possible that Great Zimbabwe may have been designed in terms of a cosmic reference or was used as an observatory at one time as one of its many functions (Bent 1893; Clark \& Carrington, 2002; Doyle \& Frank 1997; Frobenius 1923, 1931; Hall 1909; Mathivha, 1992; Stenger, 2002; Von Sicard, 1951; Wade, 2009; Wade \& Broodryk, 2010).

In this study, evidence is presented to support the hypothesis that an astronomical event in the Vela region of the sky - possibly a supernova - was associated with 14th century configured structures at Great Zimbabwe. A recent (1944) meteor event may have revitalized social ideologies related directly to the Zimbabwe-origins mythology and to current beliefs held by members of the Zion Christian Church (ZCC). The two astronomical events, despite a chronological separation of ca 700 years, represent a remarkable repetition of the cosmogenic foundations for the ZCC's mythology of "following a star", and the discussion of this forms the basis of this paper.

It is widely believed that the Lemba people originated in south Yemen and began migrating south in the mid-7th century BCE. That they had connections with Arabs is confirmed by Mullan (1969, p. 9, drawing on the earlier work of Roger Summers), who noted that 'The Lemba have undoubted connections with the Arabs...'. They are variously named Bhuba, Basena and Baphusela (Mathivha, 1992). They were also referred to as Baphusela, from Phusela near Sena. In 300-200 BCE they migrated to Zimbabwe, where they settled in the mountains at Sena II 'guided by a star which [sic] shown on top of a hill' (Mathivha, 1992, p. 3). This group split and one section moved south to Mapakomhere. The other moved to the west (Le Roux, 2010; Mathivha, 1992). Tradition relates that they were led by a star which was visible after midnight, southwards away from Sena, and that a series of settlements took place during this migration (Le Roux, 2010).

The oral tradition, which mentions some sort of star that guided the Lemba people (Le Roux, 2010; Mathivha, 1992), is mainly prevalent amongst the almost 600000 people who make up the sections of the South African population in the Mpumalanga and Limpopo Provinces as well as in the southern provinces of Zimbabwe. One group of Lemba, the Bhuba family, moved from Zimbabwe in 1910 and settled at Phusela near Lenyenye (Tzaneen), close to Zion City-Moria. There they lost their ability to see and follow the star (Le Roux, 2010) and this was interpreted as a sign that God was no longer with them. The Lemba also form part of one of the largest traditional religious groups in southern Africa today the Zion Christian Church (ZCC), who have a star as their main emblem, in common with the Zimbabwe National Flag. Here, it is interesting to note Sundkler and Steed's ( 2000, p . 836) observation that: 'two events of a cosmological and affliction-generating character inspired the forming of their groups; the threatening Halley's Comet of 1910, and the devastating "Spanish influenza" of 1919.... also, in a more general perspective, a political protest against White segregation'.

Since the first application to register the ZCC in South Africa, in 1925, there was a gradual increase from 925 members to 40000 by 1943-1944; a sudden and phenomenal expansion of the ZCC to 120000 adherents a year later took place after the inferred 1944 meteor event and centred at the zone of likely impact and fallout in the vicinity of Moria. Recent claims indicate that the overall African membership exceeds 30 million people, of whom at least a third undertakes an annual pilgrimage to Moria, the ZCC headquarters in Limpopo Province. This vast socio-political belief system emulates the magnificence of the past Great Zimbabwe complex and culture, and, we postulate, may have been reinvigorated by a 20th century meteor event that augmented the cosmogenic ideology of the present population holding to ZCC beliefs south of the Limpopo River. There is thus a fundamental connection between the ancient cosmogenic mythology of the Zimbabwe culture and the rejuvenation of these beliefs related to the 1944 meteor event. 
Secrecy surrounds the details of the meteor fragment that apparently lies under the main ZCC church built by Edward Lekganyane. After many attempts to apply for permission to the secretary-generals of the ZCC-Moria, no reply has been received. A ban has in fact been ordered restricting research into this sacred area. This may account for the absence of references in works concerning the ZCC (e.g. Anderson, 2000; Müller, 2011). This paper thus aims to examine the relationship of the earlier Zimbabwe culture to a cosmogenic event, and how the ZCC, which is inferred to be a descendant movement of this ancient civilization, may well have been reinvigorated following a second cosmogenic event, which we postulate might have been a meteor that fell near Moria during 1944.

\section{FORMATION AND GROWTH OF THE ZION CHRISTIAN CHURCH}

The ZCC was established near Great Zimbabwe (Daneel, 1970, 1971, 1974, 1988, 2001) and later became centred at Zion City-Moria, near Polokwane (Pietersburg) in South Africa, as it is believed that this is the site where a legendary "star" fell. Therefore, it is sacred land: 'The ZCC's holy city of Moriah, named after the biblical mountain, continued to provide a sacred refuge for their members' (Müller, 2011, p . 7 ) a s a challenge to economic and political power during the 1930s. Referring to the Lemba, Delius (1996, p. 45) notes that 'for many migrant workers their rural traditional home, Sekhiku-neland, provided a place of refuge in the 1930s from the ongoing impact of racist policies'. This likely also led to the annual mass pilgrimage to Moriah, which acted as a 'mag-netic force' (Müller, 2011, p. 9). In addition, 'The significance of "the mountain" in the ZCC and African Initiated Christi-anity in general appears to be a good example of cross-cultural relevance between the world represented in the Bible and the world of African tradition' (Müller, 2011, p. 124, n. 5).

The star in the flag of Zimbabwe, together with the bird of Zimbabwe, represents the symbol of the origins of their people as well as an aspiration towards socialism as confirmed by the senior leader and the President of the Lemba Cultural Association: a man with the name of Engenas started the ZCC in 1910 (Selamolela, 2008). The history of the ZCC is closely linked to a special star and the tradition of the Lemba people (K. Koka, 1999, personal communication; Moeti, 2005, personal communications in le Roux 2010, p. 298).

The progenitors of the present ZCC, their Excellencies Bishop Barnabas and Saint Engenas Lekganyane are part of a special lineage - "Lekganyane" ("kganye" = "star") meaning "the keepers of the star knowledge". Bishop Engenas Lekganyane (c. 1880-1948), great-grandfather to the present Bishop, Barnabus Lekganyane, had a vision in 1910 at a time when Halley 's Comet was very prominent in the sky. In late 1924 or early 1925, the founder Lekganyane established the ZCC at Thabakgone, and 926 adherents were claimed in 1925 when the bishop applied for state recognition of the church (Anderson, 1999). The membership in the Limpopo Province (northern South Africa) at the time the Zion Christian Church was established by the mid-1920s was thus less than 1000 members. By 1935 the membership had grown to ca 2000, and when it obtained official recognition in 1942, this had increased to 27487 adherents, spread from southern Zimbabwe, northern South Africa (including the Northern Cape region) and into Botswana; a year later $40 \quad 000-45000$ members were estimated by government (Anderson, 1999). Quite obviously the founding Bishop, Lekganyane, was a remarkable leader and also had several miracles attributed to him (Anderson, 1999).

Bishop Mutenda's centre for the Zion Church in Zimbabwe near the Great Zimbabwe ruins moved officially to Zion CityMoria, at Boyne (Daneel, 1970) at the time of the 1944 event discussed in this paper (inferred meteor). Engenas, grandfather to the present Bishop Barnabus, died four years after this event took place and affected the area surrounding the land that Bishop Engenas bought at Boyne to form the headquarters of the ZCC-Moria. Moria reflects 1 Chronicles 3:1 - a 'new Jerusalem' (Moodley, 2008, p. 75) symbolising refuge, protection, healing and cleansing. In a Truth and Reconciliation Commission interview, Motolla (1999) revealed that the membership increase after the 1944 event was profound, with ca 120000 members by 1948. The 5-pointed (as opposed to the 6-pointed Star of David) star emblem and the dove emblem of the ZCC were adopted after the 1944 event. Following Engenas Lekganyane's death in 1948, his two surviving sons, unable to resolve the succession issue, formed two factions: the majority under Edward comprised the ZCC and used the star emblem, with the minority following Joseph into what became St Engenas Zion Christian Church denoted by the dove symbol (Anderson, 1999).

\section{GEOMYTHICAL BACKGROUND}

\section{Oral tradition}

A study of the indigenous knowledge and the myths and legends of the BaLemba/BaSena/VaMwenye peoples within the Mpumalanga and Limpopo Provinces of South Africa and in the southern provinces of Zimbabwe provides insight into the founding and building of the Great Zimbabwe cultural complex and the Zimbabwe civilisation, through migrations of the people who followed some kind of star or celestial object (Arenstein \& Hamese, 2000; Mathivha, 1992; Müller, 2000; Van Warmelo, 1940; Wade, 2009, Wade \& Broodryk 2010). Professor Mathivha has recorded these in his 1992 book, which details "a star" that was visible every evening.

A significant feature is the indications of astronomic observations (under the influence of Gumbu chena Mhani) undertaken from a settlement which preceded the stellar-led migration to the locality where Great Zimbabwe was later built. This provides some substantiation for the postulate that Great Zimbabwe had cosmic references in its layout and design and may have served, amongst a range of many different functions, as an observatory (Bent 1893; Clark \& Carrington, 2002; Doyle \& Frank 1997; Frobenius 1923, 1931; Hall 1909; Mathivha, 1992; Stenger, 2002; Von Sicard, 1951; Wade, 2009; Wade \& Broodryk 2010).

The importance of the star and following that star in the beliefs of these people is obvious from the Lemba oral traditions (Mathivha, 1992, particularly pp. 3-18). The leading by a star in a westerly direction in this source resonates with the biblical star coming from the east (Matthew 2: 1-10) to Bethlehem, south west of Jerusalem. Debate about possible astronomical explanations of the star over Bethlehem has been ongoing for over 40 years (e.g. Humphreys, 1995; Kaufmanis, 1973; Landau, 2010; Mosley, 1981; Schaefer, 2013; Tipler, 2005).

\section{Great Zimbabwe as an astronomical observatory?}

From the position of the 'platform area' at Great Zimbabwe, it would appear that the Great Enclosure's main wall was used to define the backdrop of stars, with monoliths marking 
specific ascending stars and the equinox sunrises, amongst other aspects. Bent (1893) and Swan (1893) were the first to assess the ruins for any possible astronomical functions at Great Zimbabwe, followed by Hall (1909) ( Figures 1, 2 and 3). Further investigation by Doyle and Frank (1997) found Swan's assumptions incompatible with the data but con-cluded that more research was required (Figures 1 and 2). Surveys by the first author (see also Wade, 2009) found that from the platform area several arrangements exist such as the equinox sunrises, the Moon and Venus over the small conical tower (Figures 1 and 2). Prior to the construction of the main outer wall, the platform would have been used in alignment with the small conical tower to make observations on the horizon of the spring and autumn equinox sunrises. The outer wall marked Venus and the Moon with monoliths or stelae from the same vantage point and the large conical tower and outer wall are dated to $1320 \pm 20$ CE (Huffman, 2011; Vogel \& Huffman, 1991; Vogel, 1998).

The reconstructed $11 \mathrm{~m}$ conical tower in the Great Enclosure aligns with the supernova remnant RX J0852.0-4622 in Vela, as seen from the platform area, and may be a preserved structural edifice related to the Lemba legend of a star guiding them to their present homeland (Figure 2). The supernova remnant aligns with the conical tower and a monolith on the wall as viewed from the platform area (Figure 1), at an azimuth of $130^{\circ} 50^{\prime} 30 \mathrm{~A}$ when rising, and with a monolith on the wall, at an azimuth of $193^{\circ} 09^{\prime} 36 \mathrm{~A}$, when setting. In computer simulations, RX J0852.0-4622 would have risen directly over the conical tower in about the mid-13th century and then proceeded in line with the tower, on its vertical journey for most of the late evening and set at dawn, in alignment with another monolith on the western side of the main wall, for a few months of a year.

The platform area is suggestive of a stage that would effectively have placed viewers in the secluded gathering

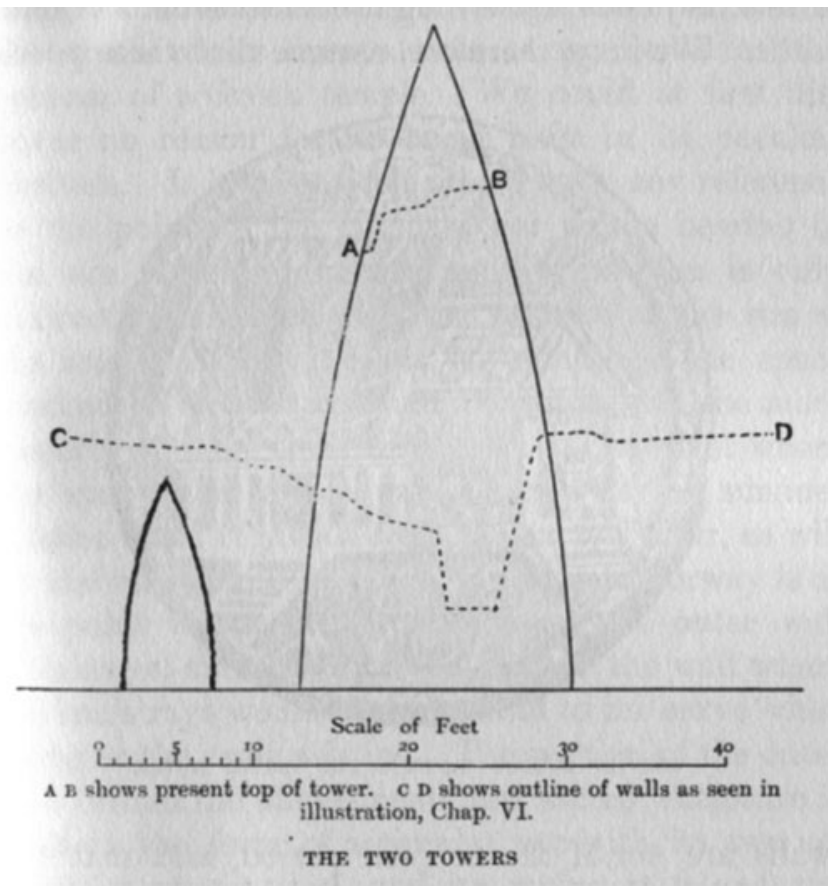

Figure 1. Large conical tower and small conical tower in the Great Enclosure at Great Zimbabwe. As reconstructed by Bent (1893) and Swan (1893). place to see the "bright star" reach the tip of the conical tower each night and perhaps during the day while visible. If the remnant was sub-luminous this "alignment" would be an extraordinary coincidence, specifically in light of the structures and oral tradition record (Figures 1-5).

\section{De-mythologizing the Lemba star-lore}

The Lemba star-lore, with conflicting chronological aspects that have yet to be demythologized, reveals in all probability that a celestial phenomenon is embedded in the oral traditions handed down by early Zimbabweans. It is still remembered in legend, and symbols such as the "ndoro" suggest very bright objects that are depicted and found in renderings on monoliths, wooden carvings and rocks facing the declinational direction of the risings and setting of the supernova remnant RX J0852.0-4622 (Chigwedere, 1996; Frobenius, 1923, 1931; Latham, 1986; Muhlanga, 1926; Von Sicard, 1951). It is notable that the route followed by the BaLemba/BaSena in their migration points towards the direction where this particular supernova would have set, with stop-over sites inhabited for short periods during the supernova's lifespan and superimposed on the vague history by descendants as "cities" (Arenstein \& Hamese, 2000; Mathivha, 1992; Wade, 2009,2012 ) (e.g. Figure 6). The Lemba's star operated as a guide and protector, and its regular reappearance was a symbol of the transitory nature of their destination until it disappeared. This was interpreted as a confirmation of the permanence of their relocation. Some allowance must be made for the chronology of settlements (termed "cities" and "suburbs" in translations of the legend and oral tradition) apparently made during the star-guided migration inherent in Lemba lore. While a supernova might be expected to fade within a matter of months, a series of inhabited localities on a migration route would imply a much greater timescale. A possible explanation for this problem could be that a small, more astronomically adept group travelled along the appar-ent celestial path over some months, thereby establishing the migration route, which was then gradually and sequentially settled at a number of locations determined by more mun-dane and practical considerations related to the needs of a larger group of people.

Ice-core data reveal that nitrate peaking appears at depths corresponding to known supernovae (Burgess \& Zuber, 2000) and a historically unrecorded supernova remnant in the Vela Region - RX J0852.0-4622 (Vela Jr) has been detected by radio, $X$-rays and the ${ }^{44} \mathrm{Ti} \gamma$-ray line. This is the likeliest remnant in the region for the time period, which we postulate could have been the scientific basis for the Lemba star lore, and which may have been portrayed as a pinpoint of light with concentric rings in the rock art and other artefacts (Aschenbach, 1998a, b; Aschenbach et al., 1995, 1999; Chen \& Gehrels, 1999; Iyudin et al., 1998, 2010; 2011; Wade, 2009).

These data relate to evidence of a similar period in suggested histories and archaeological data of southern hemisphere cultures in Australasia, South and Central America where, for some regions, the predominantly pre-literate societies' lack of historical records suggest that the cosmic event may not have been visible in those places. Comparative symbols and data are found in other examples of geomythology, and specifically emanating from Peñasco Blanco (Green and Stephenson, 2003; Krupp, 1997; Pankenier, 2006; Than, 2006), Bolivia - Lakha Manta petroglyphs (Sullivan, 1974), a Honduran Mayan Glyph at Copan (Michanowsky, 1977; Tierney, 1983) and most specifically, the Australian indigenous 


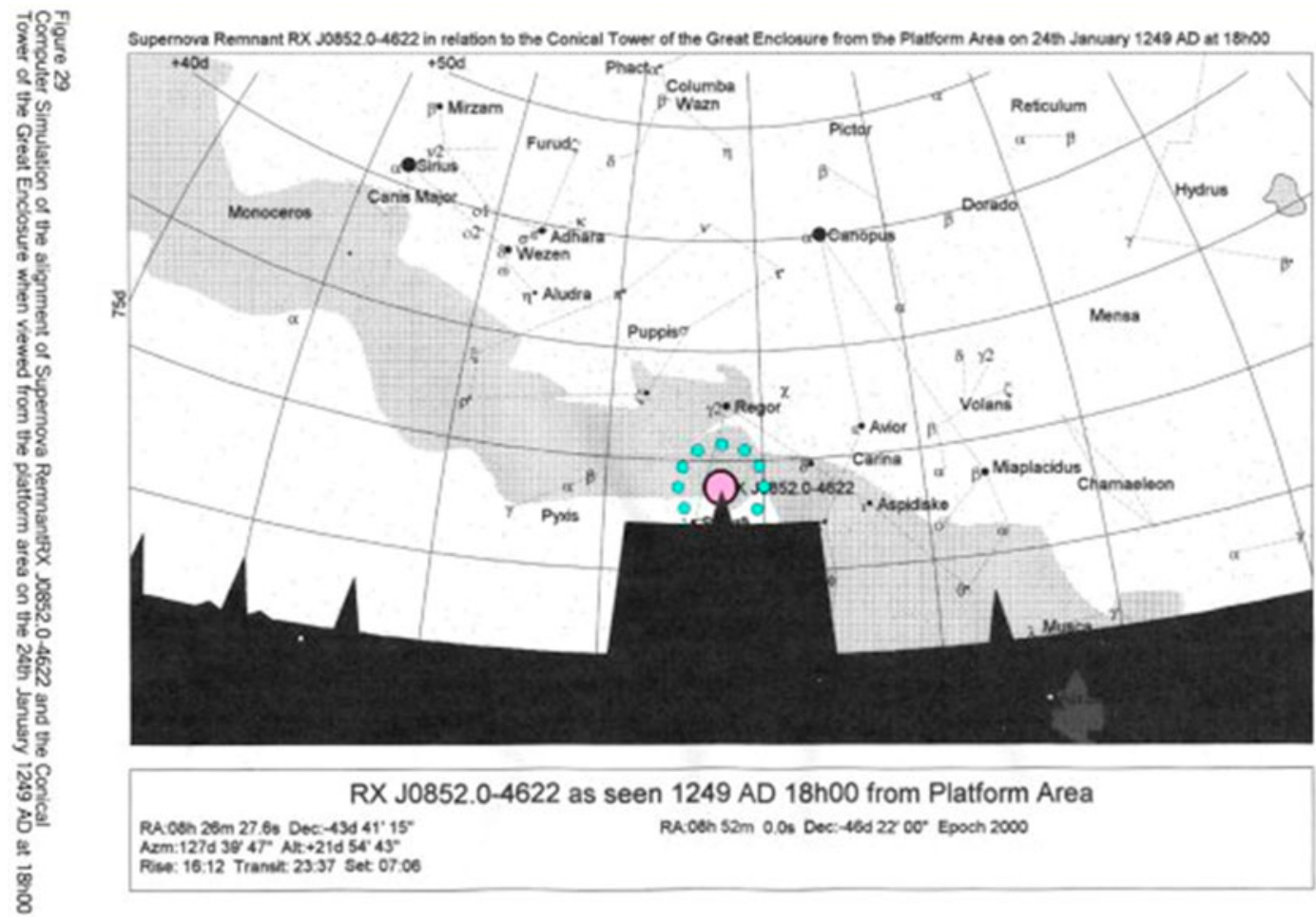

Figure 2. Supernova remnant RX J0852.0-4622 rising behind the large conical tower during the time of Great Zimbabwe's flourishing as a culture. Computer simulation by Richard P. Wade of the alignment in relation to the wall and conical tower of the Great Enclosure when viewed from the platform area at a randomly chosen date of 24 January 1249 AD at 18:00. The simulation of the large conical tower has a flat top instead of a point due to the nature of the graphics. (Courtesy of Nkwe Ridge Observatory and Bisque Software - The Sky Version IV.)

astronomy (Norris \& Hamacher, 2009, 2011) and New Zealand oral traditions of Mahutonga (Best, 1922; Green \& Orchiston, 2004; Orchiston, 2000, 2002; Sutton, 1992).

Mahutonga has been described as "... a star of the south that remains invisible" (Best, 1955, p. 46). As noted by Orchiston $(2000,2002)$, in Best (1955) there is thus the intriguing suggestion that there may be a record of a southern supernova in the Maori oral tradition as well. Orchiston (2000) has identified the overall Crux region as the likely original location of Mahutonga (Harris et al., 2013). Green and

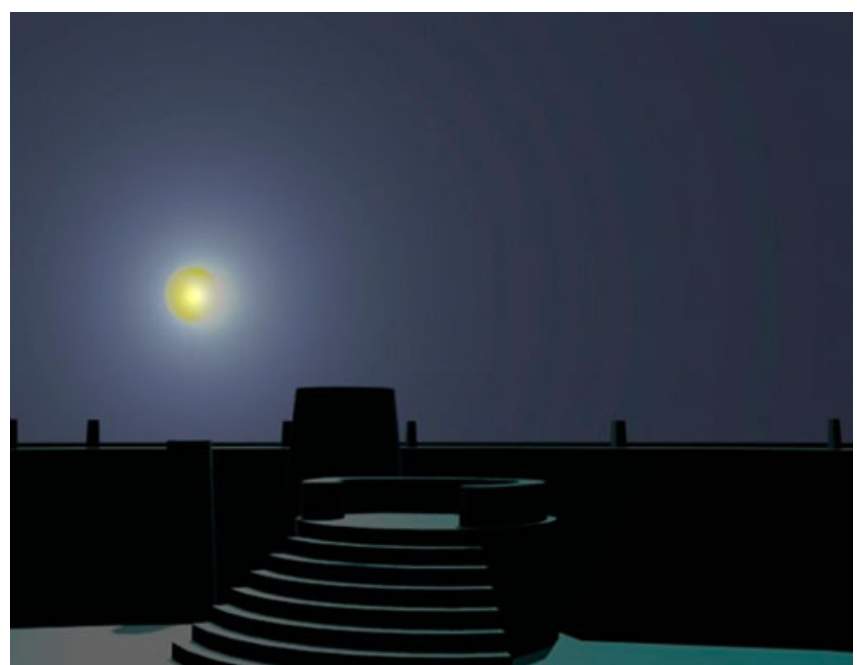

Figure 3. Reconstruction of supernova rising above the conical tower at the Great Enclosure at Great Zimbabwe, by Jan-Willem Van Bergen and Richard P. Wade.
Orchiston (2004) therefore provide an analogous southern hemisphere example, also based on oral tradition, for the geomythological cosmic reference postulate of Great Zimbabwe through their record of a Maori oral tradition of a possible supernova within the last millennium, in the general region of Crux/Velum. As New Zealand was settled at about AD 1000 by the Maori, the supernova can be placed within the last millennium (Best, 1922; Sutton, 1992; Orchiston 2000, 2002; Green \& Orchiston, 2004).

\section{AN INFERRED 1944 METEOR EVENT}

A 2006 report on a NASA website (APOD) stated that in 1944 a meteor was seen to pass over Bulawayo, Zimbabwe. Oral traditions of the Lemba, Venda and Northern Sotho people about a possible meteor that may have impacted close to Polokwane in South Africa at about the same period allow a hypothesis that they reflect the same cosmic event, and that this influenced the ZCC to build their church on or close to a meteorite impact site. Engenas Lekganyane was called from a mountain in Lesotho and guided by God to search for the star and the symbol of the tracks of cows on the "Holy Mount Zion" - similar to the mountain of miracles in the Bible. He was promised that many miracles would happen there. Lemba tradition holds that they lost the star in Zimbabwe (Mberengwa) and it moved straight and fell down at the present Moria (not far from Polokwane, Limpopo Province). The oral tradition describes hot, melted rocks, and local farmers confirm such an event, but it was remembered by them as having been in 1946 (le Roux 2010, p. 298).

This is relatively close to the 1944 date. Verification of this event was established through many years of fieldwork, surveys and eyewitness accounts of a strewn field, craters and associated ring features located $16-25 \mathrm{~km}$ from Zion 


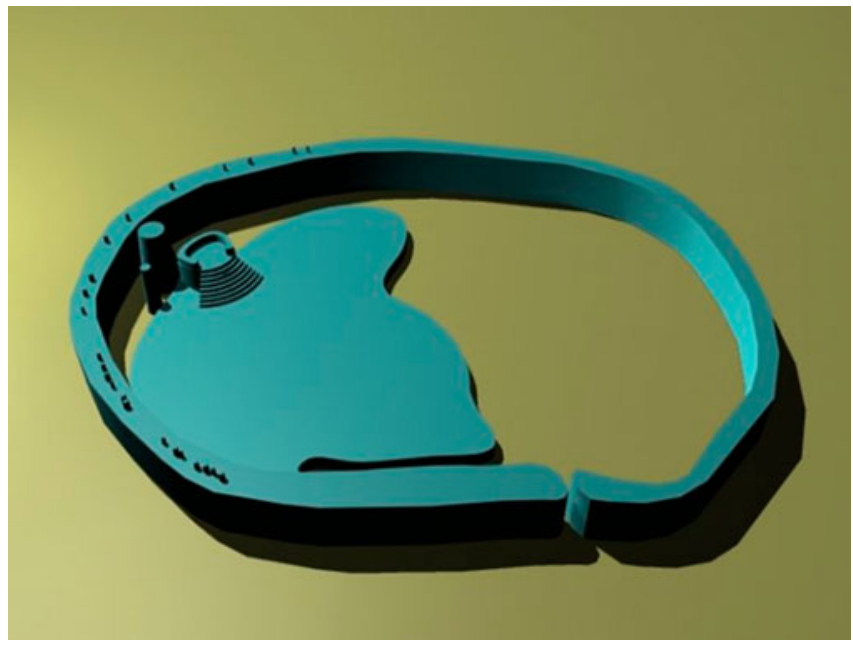

Figure 4. Reconstruction of the Great Enclosure at Great Zimbabwe showing the extent of the monoliths in relation to the platform area and conical towers, by Jan-Willem Van Bergen and Richard P. Wade.

City-Moria, where the movement has grown such that up to 7.6 million followers out of a total throughout Africa of nearly 35 million met in 2011. According to tradition, a large meteor fragment might have fallen close to Moria itself. The followers gather every year mainly to revere Easter and the memory of a star that returned since the time of their origins at Great Zimbabwe; this has revitalized some social ideologies of the Zimbabwe origins mythology to 'follow a star sent by God'.

Zion City-Moria lies approximately $450 \mathrm{~km}$ south-southeast of Bulawayo and eyewitness accounts mention that the inferred meteor event happened in the late afternoon behind and against the high point side of the Strydpoort range, on its northern-face, nearest the gorge where the Malips River runs. One eyewitness also stated that there was a large scar left in the mountain face and a hole in the mountain nearest a hill called "Mamba koppie". The meteor event apparently left a crater at an angle on the steep slopes and the trees for approximately $2 \mathrm{~km}$ around were flattened. The owners of a nearby rural store were not sure if it was a storm that had caused the devastation but they investigated the crater behind the range on the mountain and found that all the animals normally grazed there were missing or dead. The local people moved away from the area regarding it as bewitched. They mention that stones were thrown at their huts and the zone today is almost unpopulated.

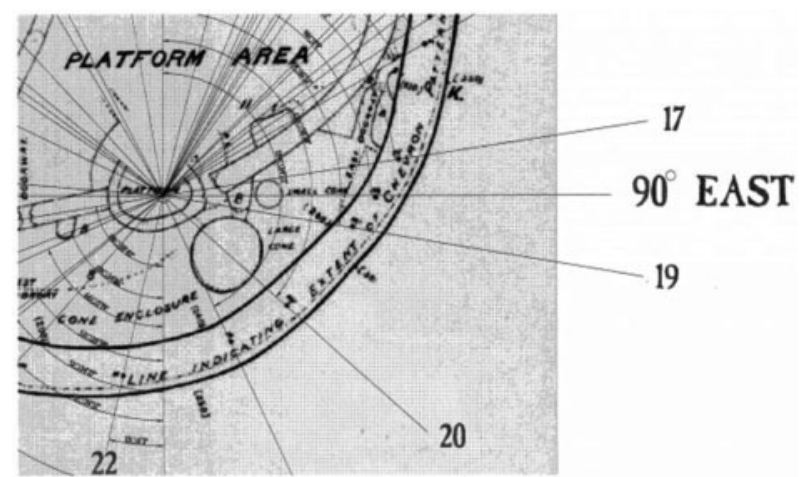

Figure 5. Detail plan of the Great Enclosure, surveying and draughtsmanship by Franklin White. Detail of reconstruction of alignments by Richard P. Wade.

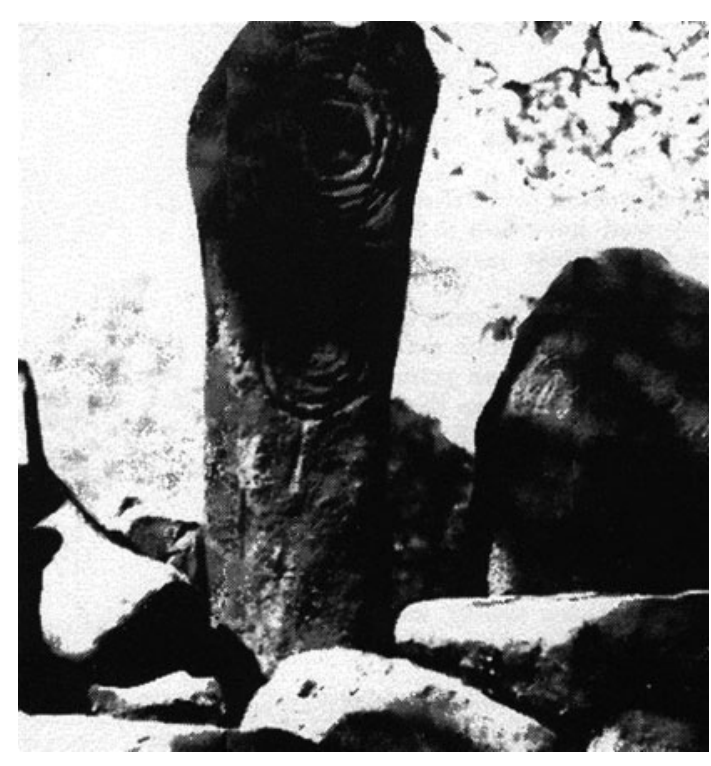

Figure 6. Milaboni's Kraal where the artist's rendition of the 'ndoro' (circle-within-circles symbol) faces the RX J0852.0-4622 setting horizon declination of $222^{\circ}$.

The main eyewitnesses that provided a record of events that day and confirmation of the date were Valerie Sharpe, King (Kgoshe) Albert Molepo, Rosina Letsoalo, Smithers Mashiya, Norman Appleton and Matjie Selina Mashitoa. Matjie Selina Mashitoa lived at the Downs in Lekgalameetse, $5 \mathrm{~km}$ from the inferred crater located at $24^{\circ} 05^{\prime} 32.34 \mathrm{~A} \mathrm{~S}: 30^{\circ} 11^{\prime}$ 7.17A E. She was born in 1938 and was six years old when she was woken by a very loud bang shortly after her sisters and brothers had retired for the night. It was early evening and they saw red flashes and stars and heard a loud 'woof woof woof' noise with flares being flung from the west to the north. The earth shook so much that there were cracks in the hut walls and things fell to the ground. It was not raining and they were terrified. Much later, when they went to fetch cattle in 1974, they found a hole where the supposed star (naledi) had fallen. On the edges of this they picked up small (approximately $30 \mathrm{~mm}$ ) metallic stones that were shiny and heavy for their size. Some of the elders still have pieces. Selina was interviewed on 25 May 2012 at Mashushu (Mafefe) $24^{\circ} 06^{\prime} 39.3 \mathrm{~A} \mathrm{~S}: 30^{\circ} 07^{\prime} 11.9 \mathrm{~A}$, roughly $8 \mathrm{~km}$ from the inferred crater. Her village area is also known as Mampas Valley.

\section{Norman Appleton eyewitness account}

During his military service in November 1944, Norman Appleton witnessed a remarkable meteor pass over Bulawayo and published a painting he made of the event (Appleton, 2000; www.astronomypictureoftheday.com NASA). In June 2006, he provided the following account in an e-mail (Appleton 2006, personal communication).

"I can confirm without a shadow of doubt that the meteor was NOT SUPERSONIC. You know my permanent interest in matters aviation and having heard so many sonic bangs from aircraft, over the years, I am $100 \%$ sure that this object was subsonic. You know that I live almost under an authorised civil aircraft flight corridor and on a fine day, I can see up to 25 jet airliners per hour passing over our garden at between 30,000 and 40,000 feet. The average speed of these aircraft is known to be around 500 miles per hour and they can take anything up to 8 minutes to pass through a visual arc of about 120 degrees - visibility permitting. The Bulawayo meteor took no more than 5 minutes to pass 
through about 100 degrees which does imply that its speed may have been fairly close to mach 1 - certainly faster than a jet airliner. One can only assume that the meteor's speed would deteriorate as it lost height and also its temperature would increase at the same rate, as it hit the higher barometric pressure of the lower atmosphere, thus resulting in its break-up. Regarding the height of the meteor, it must have been very high because the sound - that of a continuous clap of thunder (no sonic bang) did not reach me until it was almost out of sight, going away from me. The initial direction of the sound started at the point of its appearance and followed its cloud trail across the sky, i.e. the sound was traveling about 90 degrees behind the object. I know this happened a long time ago but the event is imprinted in my mind quite clearly."

His son, Phil Appleton from the California Institute of Technology, Pasadena, investigated the details of the meteor's path, and was able to provide further details from two newspaper reports, in the Bulawayo Chronicle. The first provided a date and time (ca 15:00 on 1 November 1944) for the event and speculated that it may have been ball lightning. The second report, quoting different witnesses, confirms the date, gives a time of 15:55, and notes the horizontal trajectory of the celestial object observed.

Meteorological records from the then-Southern Rhodesia were returned to the United Kingdom after the Second World War, and are stored at Exeter. Norman Appleton contacted the relevant archivist who confirmed a meteorological report from Bulawayo on 1 November 1944 stating that a "meteorite" had been observed at 15:55, but lacking any specific location. While the written sources thus agree on this possible meteor event having occurred at about 16:00 on 1 November 1944, this contrasts with Mr Appleton's painting of the event, dated December 1944; however, in a personal communication to the first author, Mr Appleton corrected this to November.

\section{The Zion City-Moria area: possible evidence for a meteor event}

A meteor fragment (or perhaps the largest fragment, accompanied by a strewn field of smaller fragments) is believed to have fallen within an area of $\leq 25 \mathrm{~km}$ radius from where Zion City-Moria now stands. In legend, the actual site is denoted by the star immediately adjacent to the Moria symbol (Figure 7). While the possible impact site of the major meteor fragment reported by eyewitnesses has not been located (and it may lie obscured beneath the Zion CityMoria built-up complex), possible strewn field fragment craters have been found and are described and illustrated below.

The Strydpoort mountain range at GaMolepo is the border between Moria and the Wolkberg region and was initially assessed for impact features in accordance with the oral traditions. It is a formidably inaccessible and unoccupied zone that recently proved hazardous even to remote sensing and air photography. The cliff face is said to have undergone a rock fall as well as a colour change when a large 'German aircraft' crashed in the early evening beyond the cliff face on a day in 1944, according to local account. A rock roughly a metre in size is said to have landed at the point now marked

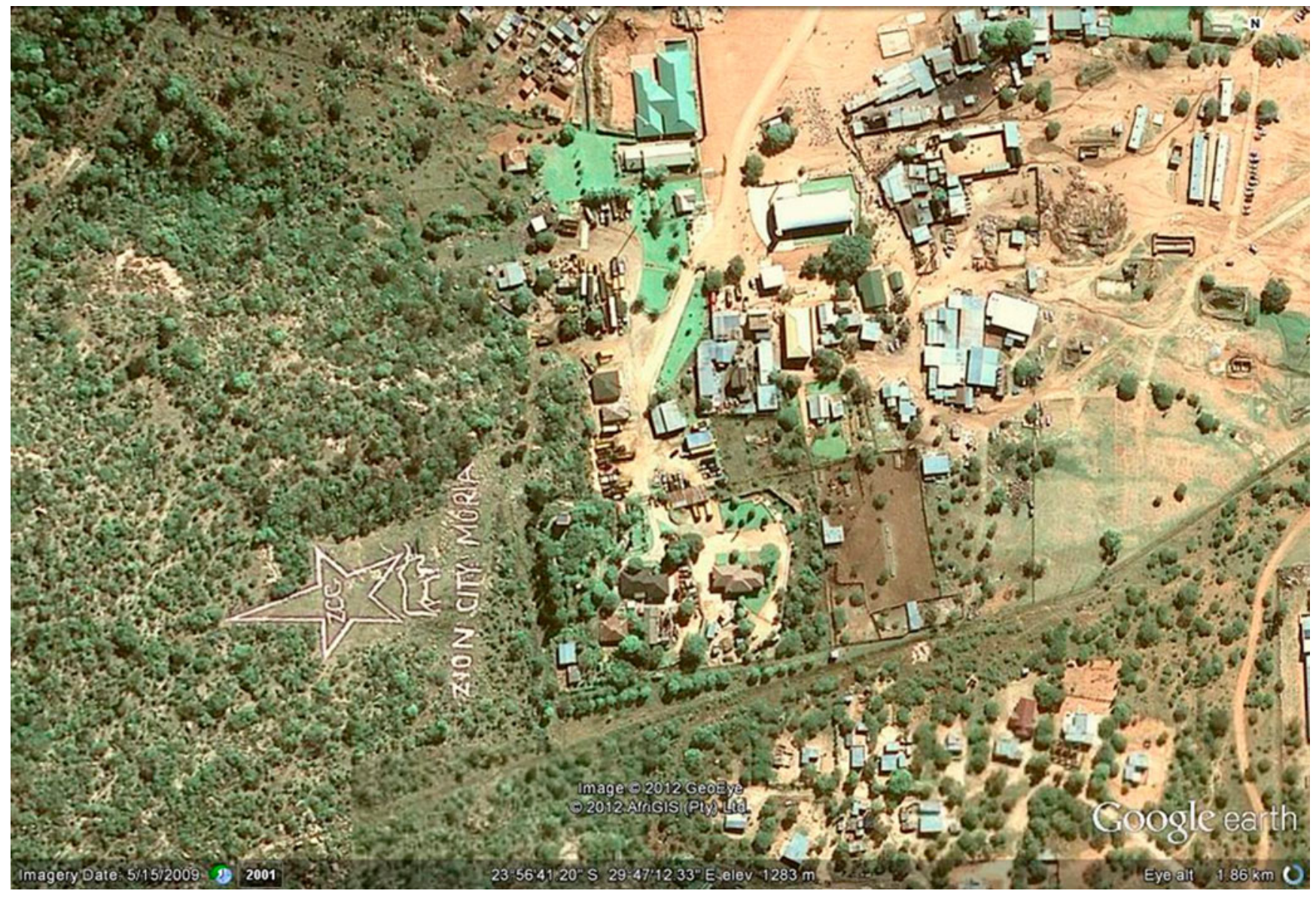

Figure 7. Headquarters of Zion City-Moria (Zion Christian Church, ZCC) near Polokwane district. The star emblem on the slope of the hill is believed to be the site where a large meteorite fell. Google Earth 15 May 2009. 
by a star emblem on the mountain and was rolled into the foundation of the church built at Moria.

At the farm Mizpah a feature was identified through remote sensing after local informants mentioned that a star fell on a ridge in the 1940s. Geomorphological indications are that it may be a crater roughly $10 \mathrm{~m}$ in diameter that has been used as a cattle watering hole.

On the mountain ridge of Mamotswiri closest to Mampas Valley in the Serala forest area, a bowl-shaped hole $20 \mathrm{~m}$ in diameter and $6 \mathrm{~m}$ deep is regarded by the villagers of Mafefe and Fertilis (10 km further east) as being the place where a star exploded violently in the early evening in November 1944. Sacred metallic stones were found at this place by the elders (Crater A, below). Another similar but smaller circular feature is seen nearby on the ridge (Crater B).

Interestingly, the GPS initially failed to guide us to the site on the ridge, possibly due to the reflectivity of the almost vertically exposed highly metamorphized quartzite strata that form the ridge, which may also explain why two aircraft crashed into the cliff face at Mamotswiri in 2011, a few hundred metres from the site at Crater A.

Rings or circular features that resemble 'fairy circles' (Juergens, 2013) have been identified by remote sensing and follow-up ground surveys roughly $3 \mathrm{~km}$ from the Mamotswiri ridge. These lie $600 \mathrm{~m}$ west of a $20 \mathrm{~m}$ long furrow about $2 \mathrm{~m}$ deep and $5 \mathrm{~m}$ wide that appears to have an exotic boulder roughly $1 \mathrm{~m}$ in size embedded in it (possible fragment of target rock dislodged by meteorite?). The original landowner's grave was erected at this site and it was revealed to us by his brother's descendants.

The terrain in which these various possible impact features occur falls partially in a nature reserve area at present and vegetation over the inferred meteor impact features prevents further investigation. However, changes in the vegetation clearly provide speciation indicators to the geomorphology that are roughly 60 years old.

- $\quad$ "Impact Furrow"
- Crater A
- Crater B
- Mizpah Crater
- Rock Fall
- Star Emblem of Moria
- Church of Moria

- Church of Moria

$24^{\circ} 7^{\prime} 46.30 \mathrm{~A} \mathrm{~S}, 30^{\circ} 11^{\prime} 51.56 \mathrm{AE}$
$24^{\circ} 7^{\prime} 51.65 \mathrm{AS}, 30^{\circ} 11^{\prime} 19.15 \mathrm{AE}$
$24^{\circ} 5^{\prime} 31.40 \mathrm{AS}, 30^{\circ} 11^{\prime} 29.83 \mathrm{AE}$
$24^{\circ} 5^{\prime} 33.77 \mathrm{AS}, 30^{\circ} 11^{\prime} 12.39 \mathrm{AE}$
$24^{\circ} 4^{\prime} 59.90 \mathrm{AS}, 29^{\circ} 54^{\prime} 26.99 \mathrm{AE}$
$24^{\circ} 2^{\prime} 56.42 \mathrm{AS}, 29^{\circ} 47^{\prime} 34.41 \mathrm{AE}$
$23^{\circ} 56^{\prime} 43.05 \mathrm{AS}, 29^{\circ} 47^{\prime} 7.96 \mathrm{AE}$
$23^{\circ} 56^{\prime} 34.34 \mathrm{AS}, 29^{\circ} 47^{\prime} 16.07 \mathrm{AE}$

\section{DISCUSSION}

We discuss here the cosmogenic geomythology of the Lemba peoples that can be tied directly with the current and very large Zion Christian Church (ZCC) of today. Oral tradition and some of the preserved architecture at Great Zimbabwe together support the concept of "following a star" in the 14th century $(1320 \pm 30 \mathrm{CE})$ southern Zimbabweannorthern South African culture, and how it was likely tied to cosmically inspired migrations along a transect marked by successive cultural-religious settlements, culminating at Great Zimbabwe. We suggest that this "star" can be reconciled with the supernova remnant RX J0852.0-4622 and that the direction in which this set, during its lifespan, determined the migration route and the location of the successive settlements. The power of such a celestial inspiration in religious terms has well known parallels with the star that the Wise Men followed at the time of Jesus' birth and in the meteorite associated with Mecca, the holy site of the Muslim Faith in Saudi Arabia (Buchner et al., 2012). Another less well known analogue is given by the Mahutonga legend in Maori oral tradition, ascribed also to a southern supernova (Orchiston, 2000). In 1910, when Halley's Comet was prominently visible in the night skies, this phenomenon led to a revitalization of the earlier Zimbabwe-culture based faith, and the ZCC fathers ("keepers of the star knowledge") subsequently established the church at Thabakgone in Limpopo Province. At this stage the ZCC had just below 1000 active followers, which had increased to ca 27000 by 1942 .

Massive growth in the Church's adherents soon after can be ascribed to a 1944 meteor event that was visible passing over Bulawayo, Zimbabwe and is thought to have fallen to Earth at Moria near Polokwane in South Africa, where the current ZCC headquarters are located. Once again, a move for the Church was implicit and once more, a massive rebirth of the star-legend-based faith was enacted by a natural cosmogenic event, leading to massive growth in ZCC membership, where today it is in excess of 30 million people. It is quite remarkable that cosmic re-enactment of the star legend has occurred at least three times in the history of the Lemba peoples, each time reaffirming their faith and promoting growth of the religion and concomitant migration of its adherents.

\section{ACKNOWLEDGEMENTS}

We thank two anonymous reviewers for their excellent advice towards improving this paper, as well as Editor-inChief Margaret Avery for her sage advice. The late Jan-Willem van Bergen made the reconstructions and Nadine Broodryk van De Wetering assisted with the research and surveys. Funding was provided by the United States Mission to South Africa. Without the assistance of Dolf Harmse and Brenda Wingfield nothing would have transpired. Norman and Phil Appleton were essential to the work and the late Jan-Willem van Bergen made the reconstructions. Nadine Broodryk van De Wetering and Reynard Bartman assisted with the research and surveys. Some funding was provided by the United States Mission to South Africa. We thank the De Cuypere family for their kind assistance throughout.

\section{REFERENCES}

ANDERson, A.H. 1999. The Lekganyanes and Prophecy in the Zion Christian Church. Journal of Religion in Africa, 29 (Facsimile 3): 285-312. DOI:10.1163/157006699X00368.

Anderson, A. 2000. Zion and Pentecost: The spirituality and experience of Pentecostal and Zionist/Apostolic churches in South Africa. Pretoria, UNISA Press.

APPLETON, N. 2000. www.astronomypictureoftheday.com NASA http:// antwrp.gsfc.nasa.gov/apod/ap001116.html (accessed 3 May 2004).

Appleton, N. \& Appleton, P. 2006. www.astronomypictureoftheday. com NASA http://spider.ipac.caltech.edu/staff/apple/WWW/statement. html (accessed 8 August 2006).

Arenstein, J. \& HAMESE, C. 2000. SA's Black Jews search for ancient lost cities. Article in the Reconstruct section of The Sunday Independent Newspaper, South Africa, 17 September 2000: 4. African Eye News Service.

AschENBACH, B. 1998a. Discovery of a young nearby supernova remnant. Nature 396(6707): 141-142. DOI:10.1038/24103.

AschenBACH, B. 1998b. Jahresbericht 1998 ROSAT. Max Plank Extraterrestrial Physics, Garching http://www.gamma.mpe-garching.mpg.de/ hcs/hcs.html (accessed 29 July 1999).

Aschenbach, B., Egger, R. \& TrüMper, J. 1995. The Vela supernova remnant: discovery of explosion fragments outside of the Vela supernova remnant shock-wave boundary (ROSAT All-Sky Survey). Nature 373: 587-590. DOI:10.1038/373587a0. 
AsCHENBACH, B., IYUdin, A.F. \& SCHONFELDER, V. 1999. Constraints of age, distance and progenitor of the supernova remnant RXJ0852.0-4622/ GROJ0852-4642. Astronomy and Astrophysics 350: 997-1006.

BENT, T. 1893. Ruined cities of Mashonaland. London, Rhodesiana Reprint Library, Volume 5 facsimile reproduction of the 3rd edition (Bulawayo, Books of Rhodesia, 1969), pp. 141-178.

BeSt, E. 1922. In Best, E. 1955. Astronomical Knowledge of the Maori. Dominion Museum Monograph No. 3 (reprinted Wellington, Government Printer, originally published 1922), p. 46.

Buchner, E., Scmieder, M., Kurat, G., Brandstatter, F., Kramar, U., NTAFLOS, T. \& KROCHERT, J. 2012. Buddha from space - an ancient object of art made of a Chinga iron meteorite fragment. Meteoritics \& Planetary Science 47(9): 1491-1501. DOI:10.1111/j.1945-5100.2012.01409.x.

Burgess, C.P. \& ZuBER, K. 2000. Footprints of the newly-discovered Vela supernova in Antarctic ice cores? Journal of Astroparticle Physics 14: 1-6. DOI:10.1016/S0927-6505(00)00102-X

CHEN, W. \& GeHrels, N. 1999. The progenitor of the new COMPTEL/ ROSAT supernova remnant in Vela. Astrophysical Journal Letters 514: L103. DOI:10.1086/311951.

Chigwedere, A. 1996. The Karanga Empire. Harare, Zimbabwe, Books for Africa.

Clark, S. \& CARRINGTON, D. 2002. 12:53 04 December 2002. Eclipse brings claim of medieval African observatory. New Scientist http://www.news cientist.com/news/print.jsp?id = ns99993137 (accessed 4 December 2002). Daneel, M.L. 1970. The God of the Matopo Hills: An essay on the Mwari cult in Rhodesia. Leiden, Mouton.

DANEEL, M.L. 1971. Old and New in Southern Shona Independent Churches. Volume I: Background and Rise of the Major Movements. The Hague, Mouton.

Daneel, M.L. 1974. Old and New in Southern Shona Independent Churches (Vol. 2). The Hague, Mouton, pp. 217-232.

Daneel, M.L. 1988. Old and New in Southern Shona Independent Churches (Vol. 3). Gweru, Zimbabwe, Mambo Press.

Daneel, M.L. 2001. African Earthkeepers: Wholistic interfaith mission. Maryknoll, Orbis.

Delius, P. 1996. A Lion amongst the Cattle: Reconstruction and resistance in the northern Transvaal. Johannesburg, Ravan.

Doyle, L. \& Frank, E. 1997. Astronomy in Africa. Encyclopedia of the History of Science, Technology, and Medicine in Non-Western Cultures. Dordrecht, Kluwer.

FrobenIUs, L. 1931. Erythräa: Lander und Zeiten des heiligen Königsmordes. Berlin, Atlantis Verlag.

FrobenIus, L. 1923. Das sterbende Afrika: Veröffentlichung des Forschungsinstitutes für Kulturmorphologie. München, O.C. Recht.

GreEN, D.A. \& ORCHISTON, W. 2004. In search of Mahutonga: a possible supernova recorded in Maori astronomical traditions? Archaeoastronomy 18: 110-113.

GREen, D.A. \& StePHENSON, F.R. 2003. Historical Supernovae. In Weiler, K. W. (Ed.) Supernovae and Gamma-Ray Bursters. Berlin, Springer Lecture Notes in Physics 598: 7-19.

HaLl, R.N. 1909. Prehistoric Rhodesia. London, Maskew \& Miller, pp. 344-345.

Harris, P., Matamua, R., Smith, T., Kerr, H. \& WaAKa, T. 2013. A review of Maori astronomy in Aotearoa-New Zealand. Journal of Astronomical History and Heritage 16(3): 325-336.

Huffman, T.N. 2011. Debating Great Zimbabwe. South African Archaeological Bulletin 66(193): 27-40.

Humphreys, C. 1995. The star of Bethlehem. Science and Christian Belief 5 (October): 83-101.

IYudin, A.F., Schönfelder,V., Bennett, K, Bloemen, H., Diehl, R., Hermsen, W., Lichti, G.G., Van Der Meulen, R.D., Ryan, J. \& Winkler, C. 1998 Emission from 44Ti associated with a previously unknown Galactic supernova. Nature 396(6707): 142-144. DOI:10.1038/24106.

IyUdin, A., Aschenbach, B., Becker, W., Dennerl, K. \& Haberl, F. 2010. XMM-Newton observations of the supernova remnant RX J0852.04622/GRO J0852-4642. Astronomy \& Astrophysics.

Iyudin, A.F., Yu. V., PAKHomov, N.N., ChugaI, J., Greiner, M., Axelsson, S., LARSSON, S. \& RYABCHIKOVA, T.A. 2011. Search for broad absorption lines in spectra of stars in the field of supernova remnant RX J0852.04622 (Vela Jr.), Astronomy \& Astrophysics, August 2011, pp. 1-9.

JuERGENS, N. 2013. The biological underpinnings of Namib Desert fairy circles. Science 339(6127): pp. 1618-1621. DOI:10.1126/science.1222999.

Kaufmanis, K. 1973. The Star of Bethlehem. Minnesota Astronomy Review 18(Fall): 3-4.

KRUPP, E.C. 1997. Skywatchers, Shamans and Kings. Hoboken, NJ, John Wiley and Sons, pp. 196-199.

LANDAU, B. 2010. Revelation of the Magi [RM]: The lost tale of the wise Men's journey to Bethlehem. New York, Harper Collins.

LATHAM, C.K.J. 1986. Mwari and the divine heroes: guardians of the Shona/pan Shona religion as an inspiration for nationality. MA thesis, Rhodes University, South Africa.

Le Roux, M. 2010. The Bhuba: a paternally inherited Jewish priesthood in southern Africa? Ekklesiastikos Pharos 92 N.S. 21: 286-304.

MathivHa, M.E.R. 1992. The Basena/Vamwenye/Balemba. Morenster, Morenster Printers.

Michanowsky, G. 1977. The Once and Future Star. New York, Hawthorn Books.

MoodLEY, E.J. 2008. Shembe, ancestors and Christ: A Christological inquiry with missiological implications. Eugene, OR, Pickwick.

Mosley, J. 1981. Common errors in "Star of Bethlehem" planetarium shows. Planetarian Third Quarter: 4-7.

Motolla, E. 1999. Zion Christian Church spokesperson Emmanuel Motolla's testimony before the Truth and Reconciliation Commission, East London, South Africa, 19 November 1999.

Muhlanga, S. (Contributed by Elaine M. Lloyd). 1926. Mbava and others. In Taylor, G.A. (Ed.) The Southern Rhodesia Native Affairs Department Annual 4: 91-92. Facsimile published 1972 by Books of Rhodesia Publishing Company, Mardon Printers.

MulLan, J.E. 1969. The Arab builders of Zimbabwe. Umtali [Mutare], Rhodesia Mission Press.

MüLleR, K. 2000. The Great Zimbabwe Supernova. Article in the Sunday Dispatches section of The Sunday Independent Newspaper, South Africa, 3 September 2000, p. 13.

MüLleR, R. 2011. African Pilgrimage: Ritual travel in South Africa's Christianity of Zion. Farnham, Ashgate.

NorRIs, R.P. \& HAMACHER, D.W. 2009. The astronomy of Aboriginal Australia. In Valls-Gabaud, D. \& Boksenberg, A. (Eds), The Role of Astronomy in Society and Culture. Proceedings of IAU Symposium No. 260, Paris, France, 19-23 January 2009.

NorRIS, R.P. \& HAMACHER, D.W. 2011. Astronomical symbolism in Australian Aboriginal rock art. Rock Art Research 28(1): 99-106.

OrChiston, W. 2000. A Polynesian astronomical perspective: the Maori of New Zealand. In Selin, H. (Ed.), Astronomy Across Cultures: A history of non-Western astronomy. Dordrecht, Kluwer, pp. 161-196.

ORCHISTON, W. 2002. Southern Hemisphere Observations. In Rickman, H. (Ed.), Highlights of Astronomy, Vol. 12. San Francisco, CA, Astronomical Society of the Pacific, pp. 322-325.

PANKenIER, D. 2006. Notes on translations of the East Asian records relating to the Supernova of AD 1054. Journal of Astronomical History and Heritage 9.1: 77-82.

SchAEFER, B.E. 2013. The Star of Bethlehem is not the Nova DO Aquilae (nor any other nova, supernova, or comet). The Observatory 133: 227-231.

StENGER, R. 2002. Star sheds light on African Stonehenge. CNN http:// www.cnn.com/2002/TECH/space/12/05/zimbabwe.observatory/index. html (accessed 5 December 2002).

Sullivan, B. 1974. SAILDART corpus 1998. 6 August 1974. Stanford Artificial Intelligence Laboratory Dump And Restore Technique. SAILDART corpus 1998 - from 229 reels of tape - as is 2002. http:// www.saildart.org/ (accessed 12 May 2011).

SundKLER, B. 1976. Zulu Zion and some Swazi Zionists. London, Oxford University Press.

SundKleR, B. \& Steed, C. 2000. A History of the Church in Africa. Cambridge, Cambridge University Press. 
SutTON, D.G. (Ed.) 1992. The Origins of the First New Zealander. Auckland, Auckland University Press.

SWAN, R.M.W. 1893. On the orientation and measurements of Zimbabwe ruins. In Bent, T. (Ed.), Ruined Cities of Mashonaland. London, Chapter 5, p. 147. Rhodesiana Reprint Library, Volume Five, facsimile reproduction of the third edition. Bulawayo, Books of Rhodesia, 1969, pp. 141-178.

THAN, K. 2006. Ancient rock art may depict exploding star. CNN http:/ www.cnn.com/. (accessed 23 May 2010).

TierneY, J. 1983. Scholar without a school. Science 4(2): p. 46.

TIPLER, FJ. 2005. The Star of Bethlehem: a Type Ia/Ic Supernova in the Andromeda Galaxy. Department of Mathematics and Department of Physics, Tulane University, New Orleans, LA 70118. http://www.math. tulane.edu/ tipler/starofbethlehem.pdf (accessed 22 August 2013).

VAn Warmelo, N.J. (ED.) 1940. The Copper Miners of Musina and the Early History of the Zoutpansberg: Vernacular accounts by S.M. Dzivhani, M.F. Mamadi, M.M. Motenda, E. Mudau. Pretoria, Government Printer, Ethnological Publications, Vol. VIII.
VogeL, J.C. 1998. Radiocarbon dating of the Iron Age sites on Greefswald (appendix). In Meyer, A. (Ed.) The Archaeological Sites of Greefswald - Stratigraphy and Chronology of the Sites and a History of Investigations. Pretoria, V \& R Printing Works.

Vogel, J.C. \& Huffman, T.N. 1991. The chronology of Great Zimbabwe. South African Archaeological Bulletin 46: 61-70. DOI:10.2307/3889086.

VON SICARD, H. 1951. The origin of the tribes in the Belingwe Reserve. In The Southern Rhodesia Native Affairs Department Annual, No. 4, December 1926. Southern Rhodesia Native Affairs Department Facsimile published 1972 by Books of Rhodesia Publishing Company. Mardon Printers, p. 17.

WADE, R.P. 2009. A systematics for interpreting past structures with possible cosmic References in Sub-Saharan Africa. MSc thesis, University of Pretoria, South Africa. http://upetd.up.ac.za/thesis/avail able/etd-05052009-174557/

WADE, R.P \& BROODRYK, N.L. 2010. Systematics of interpreting cosmic references in sub Saharan Africa. http://www.communicatingastronomy.org/cap2010/posters.html. 